\title{
Chemical and transcriptional responses of Norway spruce genotypes with different susceptibility to Heterobasidion spp. infection
}

Marie Danielsson ${ }^{1 \dagger}$, Karl Lundén ${ }^{2^{*}+}$, Malin Elfstrand ${ }^{2}$, Jiang Hu', Tao Zhao ${ }^{1}$, Jenny Arnerup ${ }^{2}$, Katarina Ihrmark ${ }^{2}$, Gunilla Swedjemark', Anna-Karin Borg-Karlson ${ }^{1}$ and Jan Stenlid ${ }^{2}$

\begin{abstract}
Background: Norway spruce [Picea abies (L.) Karst.] is one of the most important conifer species in Europe. The wood is economically important and infections by wood-rotting fungi cause substantial losses to the industry. The first line of defence in a Norway spruce tree is the bark. It is a very efficient barrier against infection based on its mechanical and chemical properties. Once an injury or an infection is recognized by the tree, induced defences are activated. In this study we examined transcriptional response, using 454-sequencing, and chemical profiles in bark of Norway spruce trees with different susceptibility to Heterobasidion annosum s.l. infection. The aim was to find associations between the transcriptome and chemical profiles to the level of susceptibility to Heterobasidion spp. in Norway spruce genotypes.
\end{abstract}

Results: Both terpene and phenol compositions were analysed and at 28 days post inoculation (dpi) high levels of 3 -carene was produced in response to $\mathrm{H}$. annosum. However, significant patterns relating to inoculation or to genotypes with higher or lower susceptibility could only be found in the phenol fraction. The levels of the flavonoid catechin, which is polymerized into proanthocyanidins (PA), showed a temporal variation; it accumulated between 5 and $15 \mathrm{dpi}$ in response to $\mathrm{H}$. annosum infection in the less susceptible genotypes. The transcriptome data suggested that the accumulation of free catechin was preceded by an induction of genes in the flavonoid and PA biosynthesis pathway such as leucoanthocyanidin reductase. Quantitative PCR analyses verified the induction of genes in the phenylpropanoid and flavonoid pathway. The GPCR data also highlighted genotype-dependent differences in the transcriptional regulation of these pathways.

Conclusions: The varying dynamics in transcriptional and chemical patterns displayed by the less susceptible genotypes suggest that there is a genotypic variation in successful spruce defence strategies against Heterobasidion. However, both high levels of piceasides and flavonoids in the less susceptible genotypes suggested the importance of the phenolic compounds in the defence. Clearly an extended comparison of the transcriptional responses in the interaction with Heterobasidion between several independent genotypes exhibiting reduced susceptibility is needed to catalogue mechanisms of successful host defence strategies.

\footnotetext{
* Correspondence: Karl.Lunden@slu.se

† Contributed equally

${ }^{2}$ Department of Forest Mycology and Plant Pathology, Swedish University of

Agricultural Sciences, Sweden

Full list of author information is available at the end of the article
} 


\section{Background}

Norway spruce [Picea abies (L.) Karst.] is one of the most important conifer species in forest ecosystems both ecologically and economically in Europe. Being long-lived organisms, spruce trees rely on both induced and constitutive defences to restrict the spread of invading fungi and insects. The first line of defence in a Norway spruce trees is the bark. The combination of the physical properties of tough lignified and suberized walls that provide a hydrophobic obstacle and the chemical properties of phenolics and terpenes makes bark a very efficient barrier against infection [1]. Once an injury or an infection is recognized by the tree, induced defences are activated, including cell wall re-enforcements, production of lytic enzymes and secondary metabolites such as phenols, stilbenes, lignans, flavonoids, and terpenes [1-4].

The root-rot fungus Heterobasidion spp. species complex is the most serious pathogen on Norway spruce in Scandinavia [5] causing root and stem rot and rendering the timber defective for sawing and pulping. Several studies indicate that genetically determined host characteristics partly determine the susceptibility of Norway spruce to Heterobasidion infections [6-11].

To protect themselves against pathogens and pests, conifers such as spruce, have evolved complex constitutive and inducible defence mechanisms [1,2]. Many of these are associated with the production of secondary metabolites to delay or stop the establishment of fungi or insects within the tree [2,12-14]. Oleoresins produced in the resin ducts in the phloem are part of the constitutive defence in the bark $[15,16]$. Upon attack, de novo differentiation of xylem resin ducts $[1,15,17]$ and production of defence-associated terpenes are reported [15,18-20]. Similarly, swelling and proliferation of polyphenolic parenchyma cells (PP cells) in the bark $[21,22]$ and changes in phenolic concentration [23-26] are seen in response to pathogen attack.

The regulation and biosynthesis of terpenes in the response to insect attack have been successfully explored using combinations of transcript profiling and chemical characterizations over the last decade $[19,27,28]$. Similar approaches have been applied on studies of flavonoids in response to leaf pathogens in poplar $[29,30]$. However, in spruce this type of approach has not yet been applied on the regulation and biosynthesis of phenolics in interaction with pathogens. From a metabolic point of view, plant phenolics constitute a much more heterogeneous group than terpenes. The phenolics are biosynthesized by several different routes but they all derive from products of the shikimic acid and phenylpropanoid pathways (Figure 1) [31].

Fungal infection commonly results in a decrease of phenolic glycosides and a subsequent increase of the corresponding aglycones $[12,14,24,26,32]$. The accumulation of aglycones could be a result of $\beta$-glucosidase activity from either the fungus [14] or the tree [33]. Possible relations between stilbene content and resistance to Heterobasidion spp. have been investigated and Lindberg et al., [12] found that the initial concentration of the stilbene astringin was negatively correlated with the depth of the hyphal penetration in Norway spruce bark. In contrast, no correlation between constitutive bark stilbene glycosides and resistance to $H$. annosum was found in Sitka spruce (Picea sitchensis [(Bong.) Carrière]) [34]. Better resistance to Ceratocystis polonica [(Siemaszko) C. Moreau] infection has been associated with low constitutive levels of the stilbene isorhapontigenin, phenol diversity and accumulation of the flavonoid (+)-catechin in the phloem of Norway spruce after inoculation $[23,25]$.

In this study we examined transcriptional response and chemical profiles in clonal Norway spruce trees. The clones were quantitatively scored for susceptibility to Heterobasidion spp. based on screening for visible decay in the stand in 2004 [7]. The present investigation was carried out in a replicate plantation in mid Sweden. For sampling we selected four genotypes (clones), two genotypes where the majority of the ramets were heavily attacked by Heterobasidion spp. and two genotypes that showed almost no infection, based on the analysis in the investigation in 2004.

Our aim was to find associations between the transcriptome and chemical profiles to the level of susceptibility to Heterobasidion spp. in Norway spruce genotypes. We found associations between the level of susceptibility and the phenol content and genotypic differences in the terpene content.

\section{Methods}

\section{Plant material and sampling}

The plant material was from a site that was part of a Swedish regional clonal forestry program at SkogForsk [35]. The stand was situated at Årdala, Sweden, (59 $01^{\prime} \mathrm{N}$, $16^{\circ} 49^{\prime} \mathrm{E}$ ) and was established in 1984 with 311 genotypes as 3-year old bare root cuttings. It was planted in a Roman square design with nine replicates and single tree plots with $1.4 \mathrm{~m}$ spacing within main plots. The genotypes were distributed in eight clone mixtures planted in different main-plots. The selected Norway spruce genotypes have previously been classified for natural susceptibility to infections of Heterobasidion spp. [7].

Three ramets per clone were used and at day 0 , two roots of each tree were chosen, one for inoculation and one for wounding treatment. The roots assigned to inoculation were artificially inoculated with Heterobasidion annosum [(Fr.) Bref.] (Sä 16-4) [36]. To allow the fungus to enter the root, three $5 \mathrm{~mm}$ circular wounds were made on a line perpendicular to the root elongation. Each bark disc was cut in half (parallel to root elongation). One half 


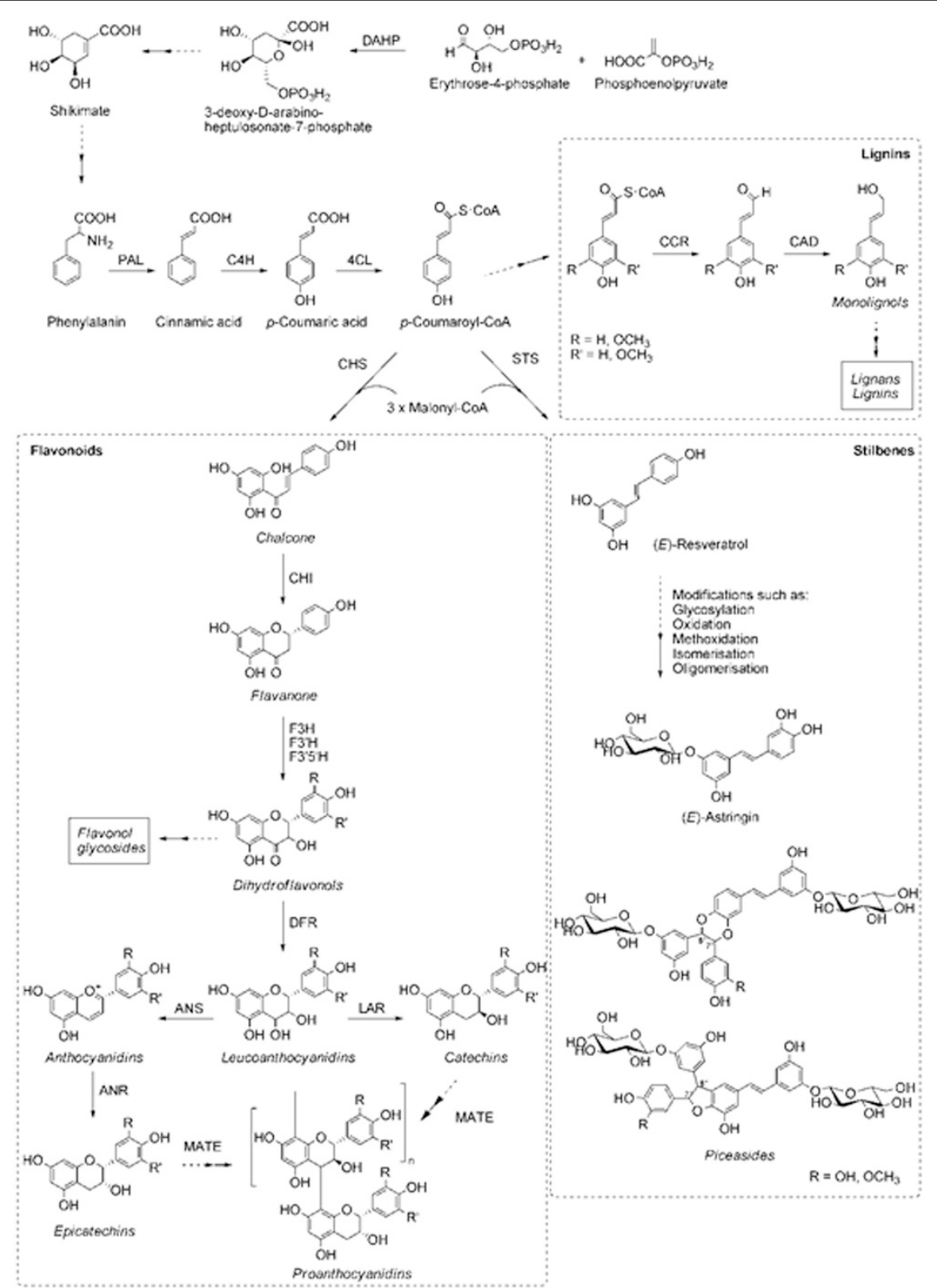

Figure 1 Secondary metabolism leading to the biosynthesis of proanthocyanidines and to the biosynthesis of stilbenes. Abbreviations: DAHP, 3-deoxy-D-arabino-heptulosonate 7-phosphate synthase; PAL, L-phenylalanine ammonia-lyase; C4H, cinnamate 4-hydroxylase; 4CL, 4coumarate CoA-ligase; CCR, cinnamoyl-CoA reductase; CAD, cinnamyl-alcohol dehydrogenase; STS, stilbene synthase; CHS, chalcone synthase; $\mathrm{CHI}$, chalcone isomerase; $\mathrm{F3H}$, flavanone 3-hydroxylase; F3'H, flavanoid 3'-hydroxylase; F3'5'H, flavanoid 3'5'-hydroxylase; DFR, dihydroflavanol reductase; ANS, anthocyanidin synthase; ANR, anthocyanidin reductase; LAR, leucoanthocyanidin reductase; MATE, multidrug and toxic compound extrusion transporter. Adapted from Mellway et al. [30].

was put in a $2 \mathrm{~mL}$ microcentrifuge tube containing $1.5 \mathrm{~mL}$ of RNAlater (Ambion) for subsequent transcriptome profiling and the other half was placed in a vial containing 1 $\mathrm{mL}$ of hexane with $57 \mathrm{ng} \mu \mathrm{L}^{-1}$ pentadecane as internal standard and $102 \mathrm{ng} \mu \mathrm{L}^{-1}$ of the antioxidant 3-tert-butyl4-hydorxyanisole for extraction of terpene content. Wooden plugs $5 \mathrm{~mm}$ in diameter and inoculated with $H$. annosum, were prepared according to Stenlid \& Swedjemark
[37], and attached to the wounds with Parafilm ${ }^{\circledR}$. The roots assigned to wounding were handled identically except that a sterile wooden plug was attached to each wound.

After five days the left inoculation point on each root was sampled. The wooden plug was removed, and thereafter a $1.5 \mathrm{~cm}$ diameter bark sample was taken around the inoculation point and the bark sample was cut in half 
(parallel to root elongation). One half was put in a $2 \mathrm{~mL}$ microcentrifuge tube containing $1.5 \mathrm{~mL}$ of RNAlater (Ambion) for subsequent transcriptome profiling and the other half was placed in a vial containing $1 \mathrm{~mL}$ of hexane with $57 \mathrm{ng} \mu \mathrm{L}^{-1}$ pentadecane as internal standard and

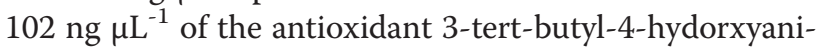
sole for extraction of terpene content. At 15 and 28 days post inoculation (dpi) the procedure was repeated for the other two inoculation holes. At $15 \mathrm{dpi}$ the inoculation point furthest to the right was collected and $28 \mathrm{dpi}$ the central point was sampled. The lesion length on the wound/inoculation point harvested at $28 \mathrm{dpi}$ was measured at $44 \mathrm{dpi}$, to validate that inoculation was successful as lesion lengths has been shown to correlate with fungal growth in field experiments $[6,8,38]$.

Temperature data were collected during the sampling period (13 August - 9 September 2008) by the data logger Tinytag ${ }^{\mathrm{TM}}$ and air temperatures ranged between $6.2^{\circ} \mathrm{C}$ and $25.8^{\circ} \mathrm{C}$.

\section{Chemical analyses \\ Chemicals}

Acetonitrile, water and formic acid, all of LC-MS grade, were purchased from Sigma Aldrich. Hexane, methanol and water of LC grade used for extractions were bought from SDS (Val de Reuil, France). n-Pentadecane was bought from Lancaster (98\% GC-purity) and 3-tert-butyl4-hydroxyanisole (BHA, $\geq 90 \%$ GC-purity) from Fluka. Vanillyl alcohol and some of the phenol reference chemicals were synthesized in the lab at KTH; other phenol reference chemicals were received as gift from Annie Yart (INRA, Orléans, France). Terpene reference chemicals were obtained from commercial sources.

\section{Preparation of samples for GC-MS and HPLC-MS analysis}

The extraction of terpenes with hexane was initiated during sampling in the field and thereafter carried out in room temperature overnight. The hexane was collected for GC-MS analysis and the residue was washed again with $1 \mathrm{~mL}$ of hexane for $1 \mathrm{~h}$. To extract phenols the hexane was removed and $0.5 \mathrm{~mL}$ of $80 \%$ methanol (with $106 \mathrm{ng} \mu \mathrm{L}^{-1}$ of vanillyl alcohol and $108 \mathrm{ng} \mu \mathrm{L}^{-1} \mathrm{BHA}$ ) was added to the sample. The extraction of phenols continued at room temperature overnight. All samples were centrifuged at $6000 \mathrm{rpm}$ for 10 minutes and stored in the freezer until analysed. The residues were placed in open vials in a ventilated cupboard and further dried in $80^{\circ} \mathrm{C}$ for 40 hours before the samples were weighed.

\section{GC-MS analyses}

Hexane samples were separated on a Varian 3400 GC with a DB-wax column $(30 \mathrm{~m}, 0.25 \mathrm{~mm}$ id and $0.15 \mu \mathrm{m}$ film thickness, J\&W Scientific, Agilent, Santa Clara, CA, USA) using the following temperature program: $40^{\circ} \mathrm{C}$ for $3 \mathrm{~min}$, ramp with $4^{\circ} \mathrm{C} / \mathrm{min}$ up to $230^{\circ} \mathrm{C}$ and kept constant for $19 \mathrm{~min}$. Injector temperature was $225^{\circ} \mathrm{C}$ and the transfer line $235^{\circ} \mathrm{C}$. Helium (0.69 bar inlet pressure) was used as carrier gas. The GC was connected to a Finnigan SSQ 7000 MS instrument with electron ionization (source: $150^{\circ} \mathrm{C}, 70 \mathrm{eV}$ ). Separations of enantiomers were performed as described by Borg-Karlson et al. [39].

\section{HPLC-ESI-MS analyses}

LC-MS analyses were performed on a Finnigan HPLC system, consisting of a Surveyor MS Pump Plus, Surveyor Autosampler Plus and Surveyor PDA Plus detector, coupled to a 2D linear ion trap, Finnigan LXQ (Thermo Fisher Scientific, San José, CA, USA).

An Ascentis express RP-amide column $(15 \mathrm{~cm}, 2.1 \mathrm{~mm}$ i.d., $2.7 \mu \mathrm{m}$ film thickness; Supelco, Bellefonte, PA, USA) together with an RP-amide guard column $(2 \mathrm{~cm}, 2.1 \mathrm{~mm}$ i.d., $5 \mu \mathrm{m}$ film thickness, Supelco, Bellefonte, PA, USA) was used for HPLC separations. The separation was carried out with a gradient of $0.1 \%$ formic acid in water (A) and $0.1 \%$ of formic acid in acetonitrile (B) and flow rate $200 \mu \mathrm{L} / \mathrm{min}$, oven temperature was $30^{\circ} \mathrm{C}$. The elution gradient was as follows (\% of B): 10\% (0-3 min), 10-30\% (3-51 $\mathrm{min}$ ), $30-100 \%$ (51-57 $\mathrm{min}$ ), hold for $11 \mathrm{~min}$ and finally decrease to $10 \% \mathrm{~B}$ during $2 \mathrm{~min}$. The system was allowed to equilibrate for 20 min between analyses.

All measurements were performed in negative mode with full scans ranging between $\mathrm{m} / \mathrm{z}$ 50-1000. The ESI source was optimized on isorhapontigenin and set up as follows: source voltage $4.00 \mathrm{kV}$, capillary temperature $270^{\circ} \mathrm{C}$, sheet gas flow $40 \mathrm{au}$ (arbitrary unit) and sweep gas $20 \mathrm{au}$. The capillary voltage was set to $-23.00 \mathrm{~V}$ and the tube lens to $-109.80 \mathrm{~V}$.

\section{Transcript profiling \\ RNA extraction, CDNA synthesis and sequencing}

Total RNA was isolated essentially as described by Chang et al. [40]. To eliminate contamination of genomic DNA the total RNA was treated with DNaseI (SIGMA) before use. RNA quality and quantity was assessed with an RNA Nano assay on a Bioanalyzer 2100 (Agilent). Poly(A)+RNA was extracted from the samples with the Dynabeads ${ }^{\circledR}$ mRNA Purification Kit (Invitrogen) according to the manufacturer's instructions. The purified mRNA was amplified with the MessageAmpIII kit (Ambion) according to the manufacturer's instruction. First strand cDNA was synthesized from the amplified RNA (aRNA) using the iScript cDNA Synthesis Kit (Bio-Rad) according to the protocol supplied by the manufacturer except that the RT-reaction was allowed to proceed over 50 minutes. Second strand synthesis was performed as described by Sambrook and Russel [41] using enzymes purchased from Fermentas. Double stranded cDNA of sufficient quality was pooled according to genotype and treatment.

Two to five $\mu \mathrm{g}$ each of $24 \mathrm{cDNA}$ samples representing all time points and treatments were submitted for template preparation and pyrosequencing on a GS FLX 
(Roche, 454) at the Norwegian Sequencing Centre http:// www.sequencing.uio.no, according to themanufacturer protocols (Roche Applied Science). Sequence reads and quality scores for sequences were obtained from the Norwegian Sequencing Centre.

\section{Verification of gene expression by $q P C R$}

Purified aRNA $(1 \mu \mathrm{g})$ from all four genotypes $(2405,7398$, 3178 and 3340) were reverse transcribed with the iScript ${ }^{\mathrm{TM}}$ cDNA synthesis kit (Bio-Rad). The cDNA synthesis was diluted 1:1 in deionizer water, and an aliquot of cDNA equivalent of $25 \mathrm{ng}$ of aRNA was used per $20 \mu \mathrm{L}$ of PCR reaction using Maxima ${ }^{\circledR}$ SYBR Green/Fluorescein qPCR Master Mix kit (Fermentas) and a final concentration of $0.5 \mu \mathrm{M}$ of each primer. Primers were designed from isotig sequences using the Primer3 software [42] with a melting temperature $(\mathrm{Tm})$ between $58^{\circ} \mathrm{C}$ and $60^{\circ} \mathrm{C}$, and amplicon length between 95-183 bp (Additional file 1). The thermal-cycling condition parameters, run on a $\mathrm{iQ}^{\mathrm{TM}} 5$ Multicolor Real-Time PCR Detection System (Bio-Rad), were as follows: $95^{\circ} \mathrm{C}$ for $10 \mathrm{~min} ; 40$ cycles of $95^{\circ} \mathrm{C}$ for $15 \mathrm{sec}, 58$ or $60^{\circ} \mathrm{C}$ for $10 \mathrm{sec}$ and $60^{\circ} \mathrm{C}$ for $1 \mathrm{~min}$. Each run was followed by a melt curve analysis to validate the specificity of the reaction. A linear plasmid standard curve was used to measure the PCR efficiency and primer pairs with efficiency lower than $95 \%$ was discarded. Two technical replicates were prepared for each sample.

Transcript abundance was normalized to the reference genes phosphoglucomutase [43], eukaryotic translation initiation factor $4 A$ (elF4A) [44] and elongation factor 1$\alpha(E L F 1 \alpha)$. The relative expression was calculated using REST 2006 [45].

\section{Bioinformatics and statistical analyses}

The sequences retrieved were assembled with the sequence assembler software Newbler v2.3 (Roche) http://my454.com/ with default settings for cDNA assembly with the sff-files as input file. The sequence assembly was carried out on the freely available Bioportal http://www.bioportal.uio.no. The combined sequences from all treatments were assembled into the gene-equivalent isogroups and the plausible splice variants, isotigs. For a detailed explanation of the terms isogroup, isotig and their connection with contigs see Ewen-Campen [46] but generally an isogroup should equal a gene, isotigs should correspond to splice variants thereof and contigs to exons. Contigs were subjected to visual inspection in ace format with the software Tablet [47]. The combined assembled sequences from all libraries was used as a reference file and were annotated with the software Blast2GO [48], where the sequences got annotated to BLASTx homologies, GO terms and EC numbers as well as scanned with InterProScan. Furthermore, the data set was trimmed for fungal sequences by identification of species belonging based on the BLAST homologies with MEGAN [49].

In order to get an estimate of relative gene expression between the libraries, count data of the occurrence of the expressed genes in the individual samples were retrieved by assembling individual reads from each library with the isogroups and isotigs in the reference file as a reference. The count data were aligned in $\mathrm{R}$ and imported into the R-package DESeq [50] and normalized on number of counts and subjected to further pair-wise differential expression transcriptome analysis.

The normalized count data were transformed to homoscedastic data in DESeq and clustered with JMPTM by Ward's hierarchical cluster. The contigs annotated into pathways leading to production of terpenes, stilbenes and proanthocyanidins were clustered separately.

$\mathrm{R}$ (The R Foundation for Statistical Computing, TU Wien, Vienna, Austria) was used for ANOVA of lesion length. Multivariate analyses were performed with the software CANOCO (Version 4.54, developed by Cajo J. F. Ter Braak and Petr Smilauer, Biometris Plant Research International, The Netherlands). Variables were subjected to log transformation, unit variance scaling and mean centring prior to ordination. Differences in constitutive concentrations of terpenes and phenols were evaluated by $\mathrm{t}$-test assuming unequal variance. Comparisons of concentrations before and after treatments were made by pairwise $\mathrm{t}$-tests on samples from the same root. The t-tests were carried out with the data analysis tool in Excel (Microsoft) after log transformation.

\section{Results \\ Inoculation}

Lesion lengths at 44 dpi were significantly longer after inoculation than after wounding alone (ANOVA, two factor with replication: $p=0.01$ ) (Table 1). However, no significant differences in lesions lengths could be found between genotypes $(p=0.36)$.

\section{Assembly}

The four sequenced genotypes rendered 492,102 reads in total and these were unevenly distributed between

Table 1 Average lesion lengths ( $\mathrm{mm}$ ) (+/- SD) for wounded and inoculated roots

\begin{tabular}{llll}
\hline Genotype & Susceptibility* & Wounded & Inoculated \\
\hline 2405 & LS & $25(0.6)$ & $33(11)$ \\
7398 & LS & $23(1.7)$ & $42(25)$ \\
3178 & HS & $24(1.7)$ & $39(8)$ \\
3340 & HS & $23(2.6)$ & $67(47)$ \\
\hline
\end{tabular}

Measured $44 \mathrm{dpi}$ at the point sampled at $28 \mathrm{dpi}, \mathrm{n}=3$.

*Highly (HS) or less (LS) susceptible according to Swedjemark [8] 
the samples (Additional file 2). The sequences were assembled and the resulting isotigs were automatically annotated (Table 2). As no reference genome is available for conifers we cannot estimate the percentage of the total genes that are covered in this data set but the numbers of possible unique transcripts are similar to previous conifer studies [51]. In this study we focused on isotigs associated with terpene- and phenylpropanoid biosynthesis.

\section{Phenols and phenylpropanoid biosynthetic pathway}

Among the constitutive phenols, two astringin dimers (piceaside $\mathrm{A} / \mathrm{B}$ and $\mathrm{G} / \mathrm{H}$ ) and one unknown phenol glucoside were found in higher concentration in bark from less susceptible genotypes $(p<0.05)$. The most obvious effect on phenol content caused by inoculation was the decrease of polar substances eluting early in the chromatogram and an increase of the late eluting, less polar compounds (Figure 2). Figure 3 shows a PCA based on the relative phenol composition of the samples. The first PC explained $19 \%$ of the variation and mainly separated the samples on time and treatment. Samples taken from the roots on the day of inoculation were placed to the left in the plot and furthest to the right were samples taken from inoculated roots at 15 or $28 \mathrm{dpi}$. The second PC had a tendency to separate the high and low susceptible genotypes. The tendency was more prominent for constitutive samples and at early stages of the inoculation; samples taken from inoculated roots at 15 and 28 dpi were not separated on a susceptibility basis (Figure 3 ). The levels of the flavonoid catechin in the bark samples were strikingly reduced at 5 dpi in comparison to the constitutive levels. Catechin accumulated significantly between 5 and 15 dpi in both $H$. annosum inoculated $(p=0.024)$ and wounded bark $(p=$ 0.003 ) and at $15 \mathrm{dpi}$ the levels of extractable catechin were comparable to the control (Figure 4). The accumulation of free catechin was more immediate in the less susceptible genotypes in response to $H$. annosum compared to in the highly susceptible genotypes (Figure 4a $p<0.05$, unpaired t-test). It should be noted that the pattern of extractable catechin varies among the genotypes; for example 3178 did not show any pronounced reduction of extractable catechin at 5 dpi compared to the control, while the reduction in 3340 was much more pronounced ( $p=$ 0.0086 , unpaired $\mathrm{t}$-test).

A cluster analysis based on the count data of isotigs (Accession number) with similarity to selected genes (phenylalanine ammonia lyase (PAL), cinnamic acid 4hydroxylase $(C 4 H)$, 4-coumarate ligase (4CL), flavanone3-hydroxylase (F3H), dihydroflavonol-4-reductase (DFR), anthocyanidin reductase (ANR), leucoanthocyanidin reductase (LAR), MATE-like, cinnamoyl CoA reductase $(C C R)$ and cinnamyl alcohol dehydrogenase $(C A D))$ in the phenylpropanoid and flavonoid pathway together with selected reference genes resulted in eight clusters (cluster 1-8, Figure 5).

Cluster 1 includes the selected reference genes that are highly expressed throughout the experiment. The isotigs in cluster 2 are all very highly expressed through all treatments. Cluster 3 contain isotigs that are significantly up-regulated at 5 dpi compared to the control, irrespective of treatment, and then remain induced throughout the experiment, such as two ANR sequences and one $L A R$ sequence (Figure 5). All of the isotigs annotated as $L A R$ are significantly up-regulated at $5 \mathrm{dpi}$ $(p<0.05)$ compared to the control. Cluster 4 includes isotigs which show a higher expression in the control and in wounded samples at 15 and $28 \mathrm{dpi}$. In cluster 5 and 6 isotigs activated in response to infection at 5 an $15 \mathrm{dpi}$ are found, for instance isotigs annotated as $P A L$, $L A R$ and $F 3 H$ (Figure 5). Interestingly, isotigs representing the genes directly involved in lignification, i.e. isotig

Table 2 Transcriptome assembly and annotation statistics

\begin{tabular}{llll}
\hline Assembly & & Annotation of isotigs & 13390 \\
\hline Total reads & 492102 & Nr. with BLASTx & homology \\
Total bases & 146391859 & Nr. GO Annotated & 468 \\
Assembled reads & 242206 & GO Annotations & 3130 \\
Inferred read error & $1.51 \%$ & Nr. with KEGG EC & 3605 \\
Q40* & $94.53 \%$ & Total KEGG EC Nr. & 483 \\
Singletons & 55334 & Nr. InterproscanTotal & 794 \\
Isogroups ("genes") & 9678 & & \\
Isotigs ("transcripts") & 14364 & & \\
Isotig N50 & 769 & & \\
Mean no. isotigs per isogroup & 1.5 & & \\
Isogroups with one Isotig & 7239 & & \\
Contigs ("exons") & 17228 & & \\
Mean no. contigs per isotig & 2 & & \\
\hline
\end{tabular}

* Q40 of contigs of at least 500 bp length 


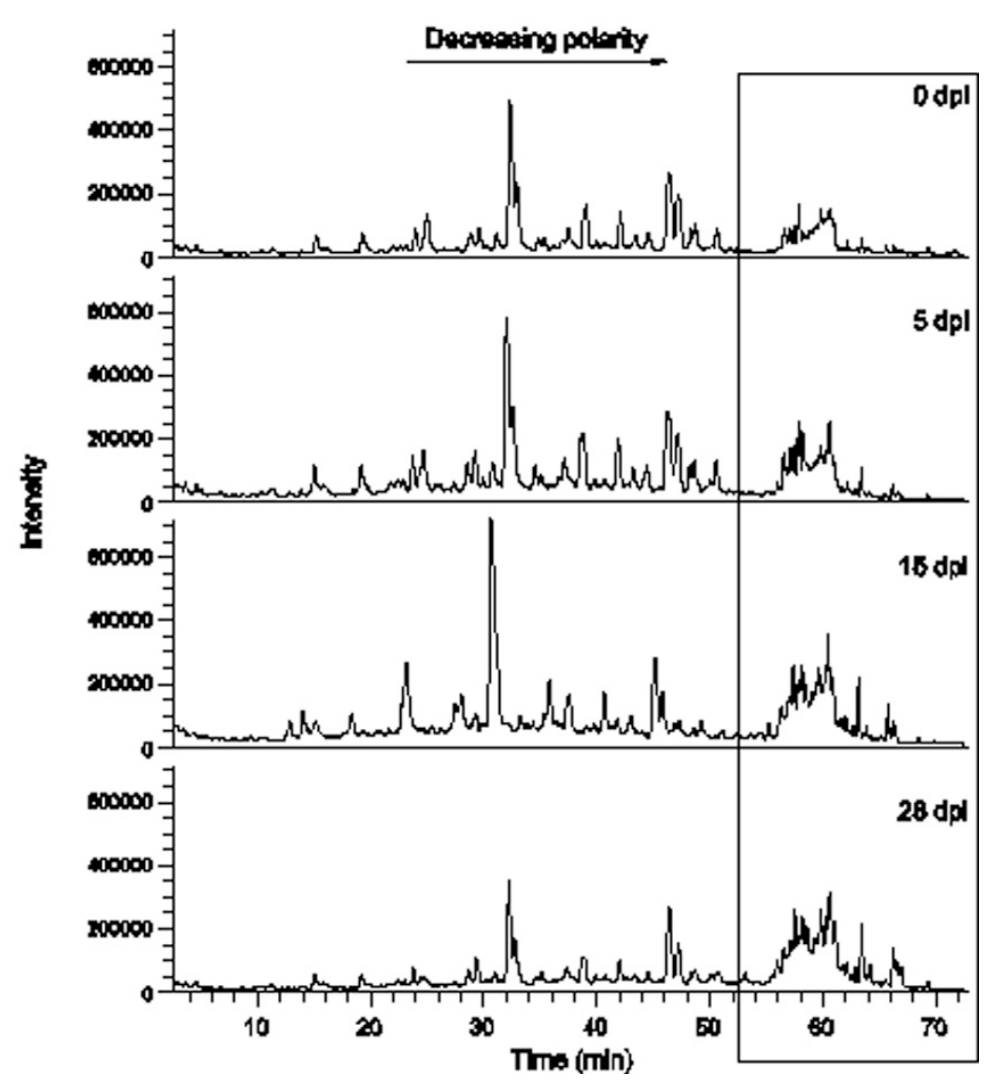

Figure 2 LC-MS chromatograms for samples taken from the same $H$. annosum-inoculated root 0, 5, 15 and 28 days post inoculation The box enhances the area where compounds with relatively low polarity elute.

$14332(C C R)$, show a transient 3-4 fold up-regulation at 5 dpi compared to the control, but a corresponding upregulation cannot be detected at 15 or $28 \mathrm{dpi}$. None of the isotigs annotated as $C A D$ show any significant regulation. Clusters 7-8 included no or very few isotigs with significant differential expression between time points.

The overall expression pattern of the isotigs associated with the phenylpropanoid and flavonoid pathways was similar in the controls (Figure 5). At 5 dpi the general expression pattern was similar for all treatments except the isotigs found in clusters 4-6. No clear separation between highly and less susceptible genotypes could be detected at 5 or $15 \mathrm{dpi}$ but the highly susceptible genotypes show more similar expression patterns after inoculation at these time points than the less susceptible genotypes (Figure 5). The observation that the less susceptible genotypes sometimes show contrasting expression patterns in response to wounding and inoculation is clearly verified in the qPCR analysis of the four genotypes (Figure 6).

The qPCR analysis of PAL,C4H,CAD, LAR and $A N R$ genes confirmed the above picture. PAL1, C4H2 and $\mathrm{C} 4 \mathrm{H} 3 / 5$ were significantly up-regulated at $5 \mathrm{dpi}$, irrespective of treatment ( $p<0.05$, Figure 6). At later time points only $\mathrm{C} 4 \mathrm{H} 2$ was significantly $(p<0.05)$ up-regulated. No significant up-regulation was observed for $C A D$. Significant regulation $(p<0.05)$ was seen for ANR2, ANR3, LAR1 and $L A R 2$ at 5 dpi (Figure 6 ) and all but $L A R 1$ stayed upregulated throughout the experiment. An isotig with similarity to the R2R3 myb transcription factor gene TT2 (transparent testa 2) showed a significant up-regulation for both treatments at all time points $(p<0.05)$. The actual levels of expression of the tested genes varied between genotypes: 7398 showed down regulation of PAL1, PAL2, $C 4 H 3 / 5$ and $C A D$ at 15 and $28 \mathrm{dpi}$ in wounding and at 28 days post $H$. annosum inoculation while 2405, for example, did not (Figure 6c, e-f).

\section{Terpenes and terpenoid biosynthesis}

The terpene content of the constitutive samples did not indicate clear differences between high and low susceptible genotypes. Both inoculation and wounding induced terpene accumulation around the wounds but no consistent alterations of terpene composition were found. A PCA based on relative terpene composition (Figure 7) tends to separate the four genotypes from each other on 

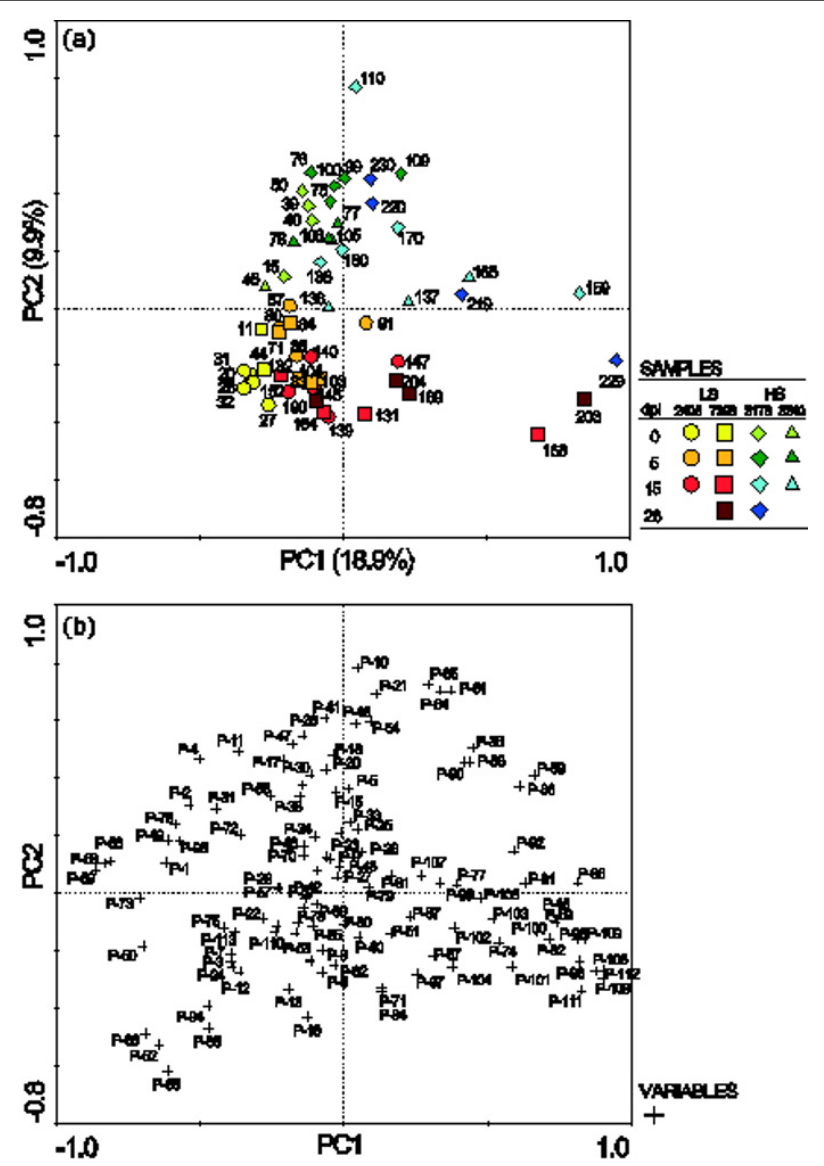

Figure 3 PCA based on relative phenol composition. (a) Sample score plot. Odd numbers: inoculated samples, even numbers: wounded samples. Less susceptible clones (LS; 2405, circles and 7398, squares) are coloured in yellow-red and highly susceptible clones (HS; 3178 , diamonds and 3340, triangles) are coloured in green-blue. The percentages of the axes states how much of the variation the PC explain. (b) Corresponding variable loading plot. The constitutive levels of P-24 (unknown glucoside), P-52 (piceaside A/B) and P-66 (piceaside G/H) were higher in samples from less susceptible clones. Further information on phenolic numbering (P-\#) is found in Additional file 3.

the first PC but this separation did not correlate with susceptibility. At 28 dpi the accumulation of 3-carene differed between treatments $(p<0.01)$ : on average $H$. annosum inoculation caused a 1200 -fold increase while wounding lead to a 70-fold increase.

A limited number of contigs with significant similarity to terpene synthase (TPS) genes were found in the dataset (Accession number). There were three contigs with significant alignment to (-)- $\alpha / \beta$-pinene synthase (PaTPSPin, [52]), each making up a separate isogroup in the dataset. One isogroup, including one isotig, showed high similarity to the previously described (+)-3-carene synthase gene [PaTPS-Car, 18]. Furthermore one contig had a significant BLASTx hit to limonene synthase (TPS-Lim) genes of Picea spp.

\section{Discussion}

This study aimed to find associations between lower susceptibility to Heterobasidion spp. in Norway spruce and changes in the transcriptome and chemical profiles among host genotypes challenged with the fungus. We used unique clone material derived from fully-grown Norway spruce trees with either high or low susceptibility to Heterobasidion spp. as measured in a field trial [7]. We selected four genotypes at a site in central Sweden, two highly susceptible and two with lower susceptibility for these comparisons. It is well established that in the interaction between Heterobasidion spp. and conifers, lesion length correlates to the fungal extension but not to the host resistance measured as sapwood growth or rot extension in the wood $[6,8,38]$. Consequently one cannot expect a lesion extension proportional to the fungal extension under field conditions. Although, we could not detect any significant differences in lesion length between genotypes at $44 \mathrm{dpi}$, we found significantly longer lesions in the inoculated wounds compared to mock inoculations. This showed that the host trees responded differently or stronger to inoculation than to wounding. 
(a)

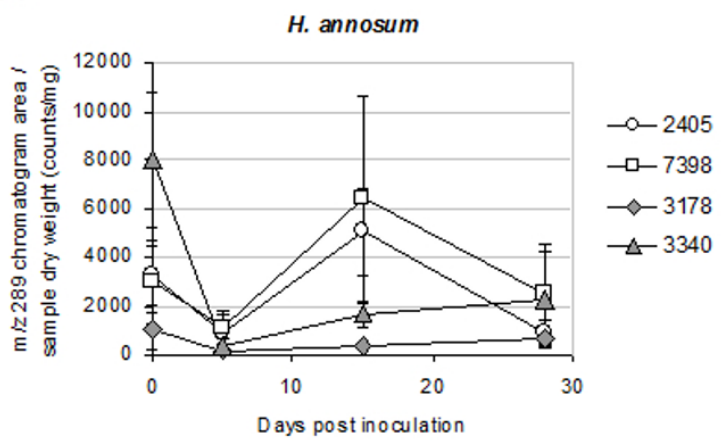

(b)

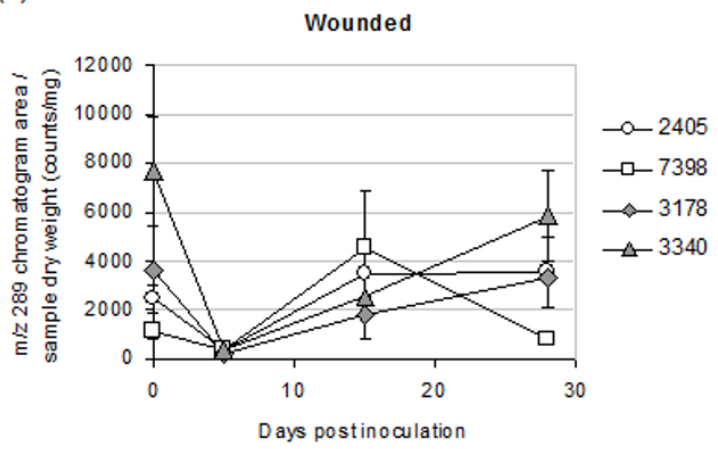

Figure 4 Average levels of (+)-catechin in $H$. annosum inoculated (a) and wounded bark (b) at 0, 5, 15 and 28 dpi. Error bar indicates SE.

Both terpene and phenol compositions were studied but patterns relating to inoculation or specific to genotypes with higher or lower susceptibility could only be found in the phenol fraction. There was a strong increase in terpenes after both wounding and inoculation, but no general qualitative differences. Instead, the most typical variation of terpene content was between the genotypes, without any correlation with resistance. The genotypedependent regulation is in agreement with the work by Zeneli and co-workers [53] who report a genotypedependent response in sapwood terpene production after treatment with methyl jasmonate. Woodward et al. [54] found a larger relative increase of 3-carene in less susceptible genotypes of Sitka spruce after inoculation with $H$. annosum in comparison with more susceptible genotypes. Our study showed no significant differences between genotypes of the two susceptibility levels. Nevertheless, inoculation caused a stronger 3-carene induction than wounding did, which is consistent with earlier findings in Norway spruce [20,55]. The expression levels of mono-TPS genes correlate with the production levels of monoterpenes in Norway spruce $[52,56]$. The isogroups with similarity to previously described Norway spruce mono-TPS genes could account for the monoterpenes identified. The absence of treatment-specific responses associated with terpenes in the chemical analyses was also reflected in the transcriptome. Although a number of sequences with significant similarity to previously described PaTPS genes were present in the data set, no consistent responses were found between treatments or between genotypes with high or low susceptibility. The overall picture of the regulation of terpenes based on the terpene profiles and the regulation of TPS genes in the transcriptome data suggests that terpenes are regulated primarily in an individual genotype-dependent manner rather than a treatment-dependent manner in this study. In Sitka spruce a small gene family of TPS-Car genes has been reported $[28,57]$ in genotypes resistant or susceptible to white pine weevil. Also (+)-3-carene and terpinolene (another major product of TPS-Car), have recently been identified as indicators for resistance against weevils in a particular geographic region of Sitka spruce origin [58]. These studies suggests that an even more focused approach, for instance involving cloning of specific TPSCar genomic sequences from individual genotypes, might be needed to address clone specific differences in terpene-based defence.

The constitutive phenolic composition differed between genotypes with high and low susceptibility but $H$. annosum inoculation lead to a differentiated phenolic 

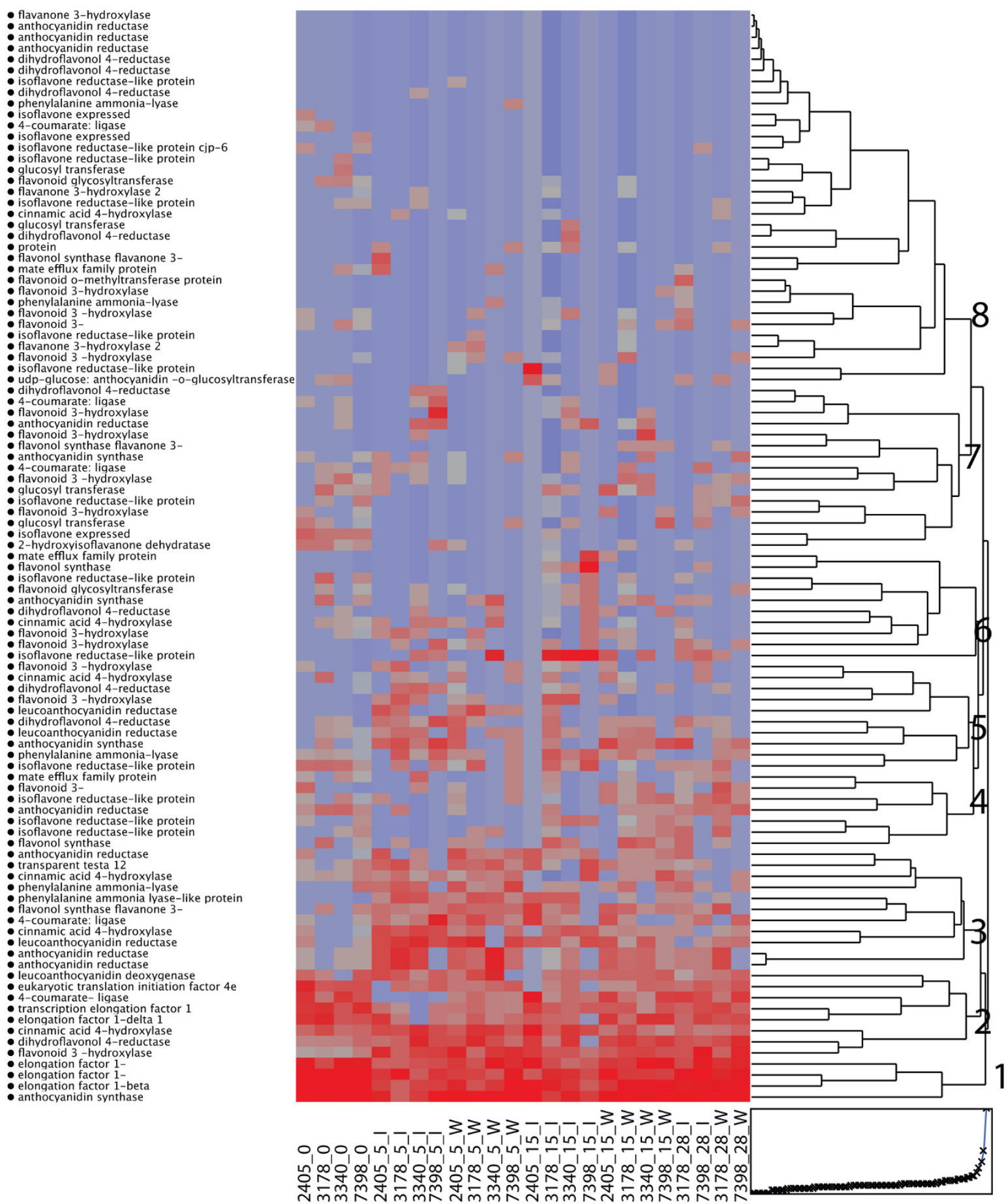

Figure 5 Hierarchical clustering of the gene expression of a subset of the sequences assembled as isotigs with a BLASTx homology to genes in the flavonoid or proanthocyanidin biosynthetic pathway. The heatmap goes from blue to red with increasing gene expression. Eight clusters (1-8) were identified as indicated in the figure. Clone number and treatment are indicated in the figure.

pattern, characterized by an increase of less polar compounds, e.g. aglycones. This is in accordance with previous findings after fungal inoculations $[12,14,24,26,32]$. Among the constitutive phenols, astringin dimers (piceasides) are found in higher concentration in samples from genotypes with low susceptiblity. Astringin was suggested to contribute to resistance against $H$. parviporum by Lindberg et al. [12] since its concentration correlated 

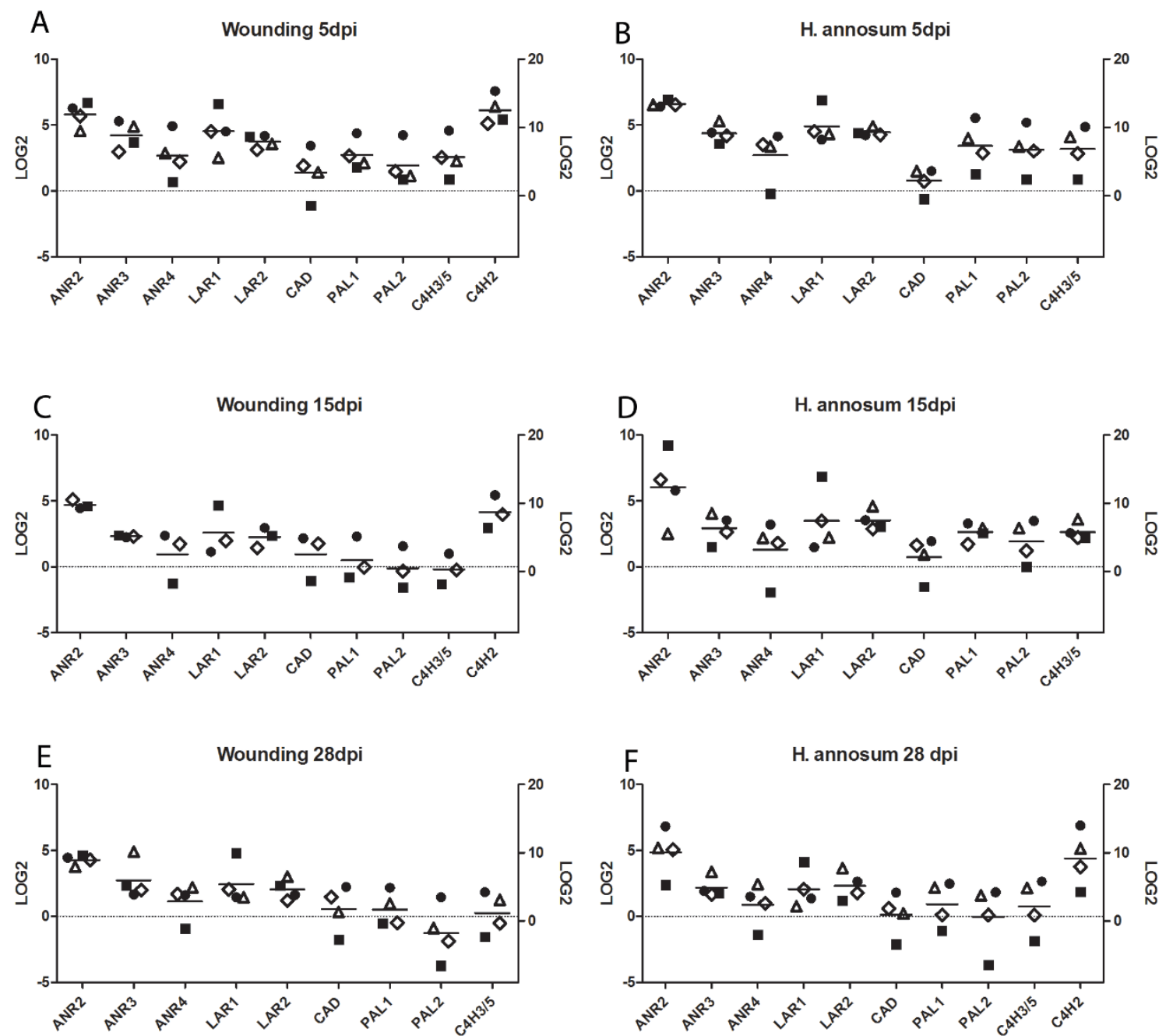

Figure 6 Relative expression of selected isotigs measured by qPCR 5 dpi (a), 15 dpi (c) and 28 dpi (e) wounding treatment and 5 dpi (b), $15 \mathrm{dpi}$ (d) and $28 \mathrm{dpi}$ (f) $\mathrm{H}$. annosum inoculation compared to untreated bark. The relative expression (Log2 values) of isotigs with significant similarity to ANR2, ANR3, ANR4, LAR1, LAR2, TT2, CAD, PAL1, PAL2 and C4H3/5 are represented on the left Y-axis and the relative expression of $\mathrm{C} 4 \mathrm{H} 2$ on the right $\mathrm{Y}$-axis. Horizontal lines correspond to the average level of expression among the four genotypes. Symbols: less susceptible clones 2405 (circles) and 7398 (squares), highly susceptible clones 3178 (diamonds) and 3340 (triangles).

negatively with hyphal growth seven days after inoculation. Stilbene dimers of astringin in Norway spruce were described the first time by Li et al. [59] and their ecological role has not yet been studied. However, viniferins, which are dimers of the stilbene resveratrol, showed antifungal activity in studies on grapevine and the dimers were generally more toxic than the monomer [60]. Our results indicate that the piceasides could be of importance in the defence system against Heterobasidion spp., but any antifungal effect remains to be shown.

Brignolas et al. [61] and Schmidt et al. [62] have suggested that activation of the biosynthetic pathways leading to flavonoids and stilbene monomers and the subsequent conversion of these into insoluble products, plays a central role in the induced defence towards wounding and fungal infection in conifers. It was suggested that resistance to $C$. polonica depends on the ability of Norway spruce to easily activate the flavonoid pathway [61]. Consequently, we were interested in whether activation of the flavonoid pathway is also of importance in the interactions with $H$. annosum. A close examination of the phenol profiles revealed that catechin accumulated significantly between 5 and 15 dpi in both $H$. annosum-inoculated and wounded bark (Figure 4). Interestingly the accumulation of free catechin was more immediate in the less susceptible genotypes in response 

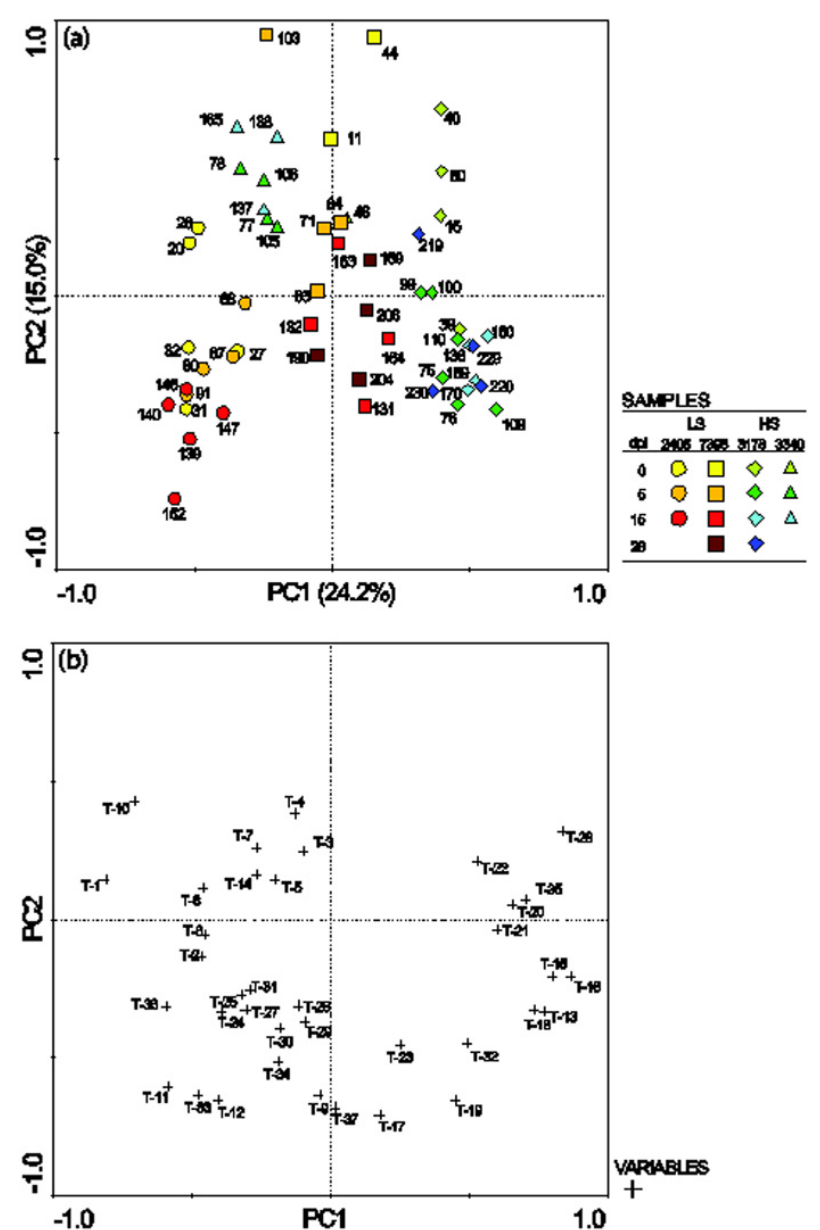

Figure 7 PCA based on relative terpene composition. (a) Sample score plot. Odd numbers: inoculated samples, even numbers: wounded samples. Less susceptible clones (LS) 2405 (circles) and 7398 (squares) are coloured in yellow-red and highly susceptible clones (HS) 3178 (diamonds) and 3340 (triangles) are coloured in green-blue. The percentages of the axes states how much of the variation the PC explain. (b) Corresponding variable loading plot. Monoterpenes (T-1-8), sesquiterpenes (T-9-19) and diterpenes (T-20-37). Further information on terpene numbering $(T-\#)$ is found in Additional file 3.

to $H$. annosum compared with the highly susceptible genotypes. A two-way clustering of the isotigs belonging to the flavonoid biosynthetic pathway was made to reveal expression patterns. This clustering contains a number of highly similar ANR and DFR isotigs with a low level of expression (cluster 1 in Figure 5). Although no one knows exactly how many members of these gene families are to be expected in spruce it is likely that these isotigs are a reflection of the quality of the assembly. Our data set had an average read length of 305 bp (Additional file 2 ), which is shorter than expected due to technical problems in the cDNA synthesis and library preparation. Also we used Newbler 2.3 to assemble this data set and Kumar and Blaxter (2010) [63]reported that this version of Newbler generates assemblies with significantly lower total lengths than newer versions of Newbler. In the case with the Milkweed transcriptome the differences between
Newbler 2.3 and later versions were not as drastic as reported by Kumar and Blaxter [46] suggesting that the impact of the assembler on the length of the assembly varies. Finally the samples consisted of a mixture of plant and fungal transcripts and in the absence of a spruce reference genome, this will affect the assembly of genes belonging to gene families present in both plants and fungi. Nevertheless differences between treatments can be found and validated by qPCR. The accumulation of catechin is preceded by a concomitant activation of genes in the phenylpropanoid pathway (PAL, C4H and $4 C L$ ) and of genes in the epicatechin and catechin biosynthetic pathways upon wounding and $H$. annosum attack (Figure $5,6)$. The strongest effect in the 454-data set is seen on the transcription of $L A R$ genes, which are significantly up-regulated at $5 \mathrm{dpi}$. The up-regulation of $L A R$ is accompanied by an up-regulation of the upstream $D F R$, 
which forms leucoanthocyanidins from which $L A R$ synthesizes catechins $[30,64]$. Up-regulation of the competing ANS (anthocyanidin synthase), which also utilizes leucoanthocyanidines as substrates to form anthocyanidines was also observed in addition to $A N R$, an enzyme that catalyzes the synthesis of epicatechins from anthocyanidins $[30,65]$. In contrast, isotigs representing genes directly involved in monolignol formation (CCR and $C A D$ do not show any significant up-regulation upon wounding or inoculation (Figure 5). This picture was confirmed by the qPCR analysis where no significant induction of $C A D$ was observed (Figure 6). However the up-regulation of $P A L$ and $C 4 H$ at 5 dpi shows that the phenlypropanoid pathway is activated. Monolignol formation and lignification is a major sink for metabolites of the phenylpropanoid pathway and the modest transcriptional regulation in this pathway following wounding and $H$. annosum inoculation may suggest that a larger proportion of the metabolites are allocated to other downstream pathways such as the flavonoid pathway as indicated by the confirmed up-regulation of $L A R$ and $A N R$ expression. Also a recent report on Sitka spruce states that $H$. annosum inoculation or wounding do not result in any significant changes in lignin content either in bark or in sapwood, but the levels of extractable phenols do increase in the bark [66].

The level of susceptibility of Norway spruce to Heterobasidion infections is partly determined by the genotype $[6,7]$. The pattern of extractable catechin in bark differ between the clones; the two less susceptible genotypes show a significantly larger increase of free catechin between 5 and 15 days than the two highly susceptible genotypes after inoculation and wounding (Figure 4). The qPCR results show that the transcriptional changes in the flavonoid pathway in response to $H$. annosum or wounding treatment are substantially different in 2405 and 7398 , the two less susceptible genotypes (Figure 6). The qPCR data may also indicate more general differences between the clones as the expression of the PAL genes, for example, is already down-regulated at $15 \mathrm{dpi}$ in wounded material of 7398 while they remain slightly up-regulated at 28 dpi irrespective of treatment in 2405 (Figure 6). The result indicates that genotype 2405 and genotype 7398 may perhaps depend on different successful defence strategies in the interaction with Heterobasidion.

\section{Conclusions}

The varying dynamics in transcription chemical patterns displayed by the less susceptible genotypes suggest that there is a genotypic variation in successful spruce defence strategies against Heterobasidion. However, both high levels of piceasides and flavonoids in the less susceptible genotypes demonstrated the importance of the phenolic compounds in defence. Clearly an extended comparison of the transcriptional responses in the interaction with Heterobasidion between several independent genotypes exhibiting reduced susceptibility is needed to catalogue mechanisms of successful host defence strategies.

\section{Additional material}

Additional file 1: qPCR primers used in the study.
Additional file 2: 454-library size and mapping metrics.
Additional file 3: Denotations of phenols in Figure 3and terpenes in
Figure 7 .

\section{Acknowledgements}

The skilled assistance of Karolin Axelsson, Joakim Halldin Stenlid, Maria Jonsson, Anders Molin and Dr. Katinka Pålsson are greatly acknowledged. The Norwegian Sequencing Centre is acknowledged for the pyrosequencing. We thank Dr. Annie Yart INRA, Orléans, France for the gift of the phenol reference chemicals and Dr. Anna Hopkins for language revision. FORMAS; The Swedish Research Council for Environment, Agricultural Sciences and Spatial Planning and SSF; Swedish Foundation for Strategic Research provided financial support.

\section{Author details}

${ }^{1}$ Ecological Chemistry Group, Department of Chemistry, KTH, Sweden. ${ }^{2}$ Department of Forest Mycology and Plant Pathology, Swedish University of Agricultural Sciences, Sweden.

\section{Authors' contributions}

MD conceived the study, did the field experiment, the analysis of phenols, the chemical analysis statistics and, assisted in the drafting of the manuscript $\mathrm{KL}$ conceived the study, did the field experiment, assisted in the sample preparation and the drafting of the manuscript and did the transcriptome analysis statistics, ME did the sample preparation, drafted the manuscript and assisted in the transcriptome analysis $\mathrm{JH}$ assisted in the terpene compound analysis, TZ did the terpene compound analysis, JA performed the $\mathrm{qPCR}, \mathrm{KI}$ assisted in the sample preparation, GS assisted in the design of the study, A-KB-Kassisted in drafting the manuscript, JS conceived the study and assisted in drafting the manuscript. All authors read and approved the final manuscript

Received: 9 June 2011 Accepted: 8 November 2011

Published: 8 November 2011

\section{References}

1. Franceschi VR, Krokene P, Christiansen E, Krekling T: Anatomical and chemical defenses of conifer bark against bark beetles and other pests. New Phytologist 2005, 167(2):353-375.

2. Keeling Cl, Bohlmann J: Genes, enzymes and chemicals of terpenoid diversity in the constitutive and induced defence of conifers against insects and pathogens. New Phytologist 2006, 170(4):657-675.

3. Ralph SG, Yueh H, Friedmann M, Aeschliman D, Zeznik JA, Nelson CC, Butterfield YSN, Kirkpatrick R, Liu J, Jones SJM, et al: Conifer defence against insects: microarray gene expression profiling of Sitka spruce (Picea sitchensis) induced by mechanical wounding or feeding by spruce budworms (Choristoneura occidentalis) or white pine weevils (Pissodes strobi) reveals large-scale changes of the host transcriptome. Plant Cell and Environment 2006, 29(8):1545-1570.

4. Witzell J, Martin JA: Phenolic metabolites in the resistance of northern forest trees to pathogens - past experiences and future prospects. Canadian Journal of Forest Research-Revue Canadienne De Recherche Forestiere 2008, 38(11):2711-2727.

5. Bendz-Hellgren M, Lipponen K, Solheim H, Thomsen IM: Impact, control and managment of Heterobasidion annosum root and but rot in Europe and North America. In Heterobasidion annosum biology, ecology, impact 
and control. Edited by: Woodward S, Stenlid J, Karjalainen R, Hüttermann A. Wallingford: CAB International; 1998:333-345.

6. Arnerup J, Swedjemark G, Elfstrand M, Karlsson B, Stenlid J: Variation in growth of Heterobasidion parviporum in a full-sib family of Picea abies. Scandinavian Journal of Forest Research 2010, 25(2):106-110.

7. Karlsson B, Swedjemark G: Genotypic variation in natural infection frequency of Heterobasidion spp. in a Picea abies clone trial in southern Sweden. Scandinavian Journal of Forest Research 2006, 21(2):108-114.

8. Swedjemark G, Karlsson B: Genotypic variation in susceptibility following artificial Heterobasidion annosum inoculation of Picea abies clones in a 17-year-old field test. Scandinavian Journal of Forest Research 2004, 19(2):103-111.

9. Swedjemark G, Stenlid J: Between-tree and between-isolate variation for growth of S-group Heterobasidion annosum in sapwood of Picea abies cuttings. Canadian Journal of Forest Research-Revue Canadienne De Recherche Forestiere 1997, 27(5):711-715.

10. Swedjemark G, Stenlid J, Karlsson B: Genetic variation among clones of Picea abies in resistance to growth of Heterobasidion annosum. Silvae Genetica 1998, 46(6):369-374.

11. von Weissenberg K: Variation in relative resistance to spread of Fomes annosus in four clones of Picea abies. European Journal of forest Pathology 1975, 5(2):112-117

12. Lindberg $M$, Lundgren $L$, Gref $R$, Johansson $M$ : Stilbenes and resin acids in relation to the penetration of Heterobasidion annosum through the bark of Picea abies. European Journal of Forest Pathology 1992, 22(2-3):95-106.

13. Seybold S, Huber D, Lee J, Graves A, Bohlmann J: Pine monoterpenes and pine bark beetles: a marriage of convenience for defense and chemical communication. Phytochemistry Reviews 2006, 5(1):143-178.

14. Woodward S, Pearce RB: The role of stilbenes in resistance of Sitka spruce (Picea sitchensis (Bong) Carr) to entry of fungal pathogens. Physiological and Molecular Plant Pathology 1988, 33(1):127-149.

15. Martin D, Tholl D, Gershenzon J, Bohlmann J: Methyl jasmonate induces traumatic resin ducts, terpenoid resin biosynthesis, and terpenoid accumulation in developing xylem of Norway spruce stems. Plant Physiology 2002, 129(3):1003-1018.

16. Phillips MA, Croteau RB: Resin-based defenses in conif. Trends in plant science 1999, 4(5):1360-1385.

17. Nagy NE, Franceschi VR, Solheim H, Krekling T, Christiansen E: Woundinduced traumatic resin duct development in stems of Norway spruce (Pinaceae): Anatomy and cytochemical traits. American Journal of Botany 2000, 87(3):302-313.

18. Fäldt J, Martin D, Miller B, Rawat S, Bohlmann J: Traumatic resin defense in Norway spruce (Picea abies): Methyl jasmonate-induced terpene synthase gene expression, and cDNA cloning and functional characterization of (+)-3-carene synthase. Plant Molecular Biology 2003, 51(1):119-133.

19. Miller B, Madilao LL, Ralph S, Bohlmann J: Insect-induced conifer defense. White pine weevil and methyl jasmonate induce traumatic resinosis, de novo formed volatile emissions, and accumulation of terpenoid synthase and putative octadecanoid pathway transcripts in Sitka spruce. Plant Physiology 2005, 137(1):369-382.

20. Zamponi L, Michelozzi M, Capretti P: Terpene response of Picea abies and Abies alba to infection with Heterobasidion s.l. Forest Pathology 2007 37(4):243-250.

21. Franceschi VR, Krekling T, Christiansen E: Application of methyl jasmonate on Picea abies (Pinaceae) stems induces defense-related responses in phloem and xylem. American Journal of Botany 2002, 89(4):578-586.

22. Nagy NE, Fossdal CG, Krokene P, Krekling T, Lonneborg A, Solheim H: Induced responses to pathogen infection in Norway spruce phloem: changes in polyphenolic parenchyma cells, chalcone synthase transcript levels and peroxidase activity. Tree Physiology 2004, 24(5):505-515.

23. Lieutier F, Brignolas F, Sauvard D, Yart A, Galet C, Brunet M, Van De Sype H: Intra- and inter-provenance variability in phloem phenols of Picea abies and relationship to a bark beetle-associated fungus. Tree Physiology 2003, 23(4):247-256.

24. Viiri $H$, Annila $E$, Kitunen $V$, Niemela P: Induced responses in stilbenes and terpenes in fertilized Norway spruce after inoculation with blue-stain fungus, Ceratocystis polonica. Trees-Structure and Function 2001, 15(2):112-122.

25. Brignolas F, Lieutier F, Sauvard D, Christiansen E, Berryman AA: Phenolic predictors for Norway spruce resistance to the bark beetle Ips typographus (Coleoptera: Scolytidae) and an associated fungus,
Ceratocystis polonica. Canadian Journal of Forest Research 1998 28(5):720-728.

26. Brignolas F, Lieutier F, Sauvard D, Yart A, Drouet A, Claudot AC: Changes in soluble-phenol content of Norway spruce (Picea abies) phloem in response to wounding and inoculation with Ophiostoma polonicum. European Journal of Forest Pathology 1995, 25(5):253-265.

27. Lippert D, Chowrira S, Ralph SG, Zhuang J, Aeschliman D, Ritland C, Ritland K, Bohlmann J: Conifer defense against insects: Proteome analysis of Sitka spruce (Picea sitchensis) bark induced by mechanical wounding or feeding by white pine weevils (Pissodes strobi). Proteomics 2007, 7(2):248-270.

28. Hall DE, Robert JA, Keeling Cl, Domanski D, Quesada AL, Jancsik S, Kuzyk MA, Hamberger B, Borchers CH, Bohlmann J: An integrated genomic, proteomic and biochemical analysis of (+)-3-carene biosynthesis in Sitka spruce (Picea sitchensis) genotypes that are resistant or susceptible to white pine weevil. Plant J 2011, 65(6):936-948

29. Miranda M, Ralph SG, Mellway R, White R, Heath MC, Bohlmann J, Constabel CP: The transcriptional response of hybrid poplar (Populus trichocarpa $\times$ P-deltoides) to infection by Melampsora medusae leaf rust involves induction of flavonoid pathway genes leading to the accumulation of proanthocyanidins. Mol Plant-Microbe Interact 2007, 20(7):816-831.

30. Mellway RD, Tran LT, Prouse MB, Campbell MM, Constabel CP: The woundpathogen-, and ultraviolet B-responsive MYB134 gene encodes an R2R3 MYB transcription factor that regulates proanthocyanidin synthesis in poplar. Plant Physiology 2009, 150(2):924-941.

31. Herrmann KM: The shikimate pathway as an entry to aromatic secondary metabolism. Plant Physiology 1995, 107(1):7-12.

32. Johansson SM, Lundgren LN, Asiegbu FO: Initial reactions in sapwood of Norway spruce and Scots pine after wounding and infection by Heterobasidion parviporum and H. annosum. Forest Pathology 2004, 34(3):197-210.

33. Johansson M, Stenlid J: Infection of roots of Norway spruce (Picea abies) by Heterobasidion annosum. 1. Initial reactions in sapwood by wounding and infection. European Journal of Forest Pathology 1985, 15(1):32-45.

34. Toscano Underwood CD, Pearce RB: Stilbene glucoside levels and the resistance of Sitka spruce (Picea sitchensis) tissues to colonization by root- and butt-rotting fungi. Plant Pathology 1992, 41(6):722-729.

35. Karlsson B, Högberg KA: Genotypic parameters and clone $x$ site interaction in clone tests of Norway spruce (Picea abies (L.) Karst.). Forest Genetics 1998, 5:21-30.

36. Stenlid J, Karlsson J-O: Partial intersterility in Heterobasidion annosum. Mycological Research 1991, 95(10):1153-1159.

37. Stenlid J, Swedjemark G: Differential growth of S- and P-isolates of Heterobasidion annosum in Picea abies and Pinus sylvestris. Transactions of the British Mycological Society 1988, 90(2):209-213.

38. Hietala AM, Eikenes M, Kvaalen H, Solheim H, Fossdal CG: Multiplex realtime PCR for monitoring Heterobasidion annosum colonization in Norway spruce clones that differ in disease resistance. Applied and Environmental Microbiology 2003, 69(8):4413-4420.

39. Borg-Karlson A-K, Lindström M, Norin T, Persson M, Valterova I: Enantiomeric composition of monoterpene hydrocarbons in different tissues of Norway spruce, Picea abies (L) Karst. - A multidimensional gaschromatography study. Acta Chem Scand 1993, 47(2):138-144.

40. Chang SJ, Puryear J, Cairney J: A simple and efficient method for isolating RNA from pine trees. Plant Molecular Biology Reporter 1993, 11(2):113-116.

41. Sambrook J, Russel D: Molecular cloning: A laboratory manual. New York: Cold srping harbor laboratory press; 32001.

42. Primer 3. [http://biotools.umassmed.edu/bioapps/primer3_www.cgi].

43. Vestman D, Larsson E, Uddenberg D, Cairney J, Clapham D, Sundberg E, von Arnold S: Important processes during differentiation and early development of somatic embryos of Norway spruce as revealed by changes in global gene expression. Tree Genetics \& Genomes 2010, 7(2):347-362.

44. Palovaara J, Hakman I: Conifer WOX-related homeodomain transcription factors, developmental consideration and expression dynamic of WOX2 during Picea abies somatic embryogenesis. Plant Molecular Biology 2008, 66(5):533-549

45. Pfaffl MW, Horgan GW, Dempfle L: Relative expression software tool (REST (c)) for group-wise comparison and statistical analysis of relative expression results in real-time PCR. Nucleic Acids Research 2002, 30(9):10. 
46. Ewen-Campen B, Shaner N, Panfilio K, Suzuki Y, Roth S, Extavour C: The maternal and early embryonic transcriptome of the milkweed bug Oncopeltus fasciatus. BMC Genomics 2011, 12(1):61.

47. Milne I, Bayer M, Cardle L, Shaw P, Stephen G, Wright F, Marshall D: Tablet - next generation sequence assembly visualization. Bioinformatics 2010, 26(3):401-402.

48. Conesa A, Götz S, García-Gómez JM, Terol J, Taón M, Robles M: Blast2GO: a universal tool for annotation, visualization and analysis in functional genomics research. Bioinformatics 2005, 21(18):3674-3676.

49. Mitra S, Klar B, Huson DH: Visual and statistical comparison of metagenomes. Bioinformatics 2009, 25(15):1849-1855.

50. Anders $\mathrm{S}$, Huber W: Differential expression analysis for sequence count data. Genome Biology 2010, 11(10):R106.

51. Ralph S, Chun H, Kolosova N, Cooper D, Oddy C, Ritland C, Kirkpatrick R, Moore R, Barber S, Holt R, et al: A conifer genomics resource of 200,000 spruce (Picea spp.) ESTs and 6,464 high-quality, sequence-finished fulllength cDNAs for Sitka spruce (Picea sitchensis). BMC Genomics 2008, 9(1):484.

52. Martin DM, Faldt J, Bohlmann J: Functional characterization of nine Norway spruce TPS genes and evolution of gymnosperm terpene synthases of the TPS-d subfamily. Plant Physiology 2004, 135(4):1908-1927.

53. Zeneli $G$, Krokene P, Christiansen E, Krekling T, Gershenzon J: Methyl jasmonate treatment of mature Norway spruce (Picea abies) trees increases the accumulation of terpenoid resin components and protects against infection by Ceratocystis polonica, a bark beetle-associated fungus. Tree Physiology 2006, 26(8):977-988.

54. Woodward S, Bianchi S, Bodles WJA, Beckett L, Michelozzi M: Physical and chemical responses of Sitka spruce (Picea sitchensis) clones to colonization by Heterobasidion annosum as potential markers for relative host susceptibility. Tree Physiology 2007, 27(12):1701-1710.

55. Zhao T, Krokene P, Björklund $N$, Långström B, Solheim $H$, Christiansen $E$, Borg-Karlson A-K: The influence of Ceratocystis polonica inoculation and methyl jasmonate application on terpene chemistry of Norway spruce, Picea abies. Phytochemistry 2010, 71(11-12):1332-1341.

56. Zulak KG, Lippert DN, Kuzyk MA, Domanski D, Chou T, Borchers CH, Bohlmann J: Targeted proteomics using selected reaction monitoring reveals the induction of specific terpene synthases in a multi-level study of methyl jasmonate-treated Norway spruce (Picea abies). Plant J 2009, 60(6):1015-1030

57. Keeling Cl, Weisshaar S, Ralph SG, Jancsik S, Hamberger B, Dullat HK, Bohlmann J: Transcriptome mining, functional characterization, and phylogeny of a large terpene synthase gene family in spruce (Picea spp.). BMC Plant Biol 2011, 11.

58. Robert JA, Madilao LL, White R, Yanchuk A, King J, Bohlmann J: Terpenoid metabolite profiling in Sitka spruce identifies association of dehydroabietic acid, (+)-3-carene, and terpinolene with resistance against white pine weevil. Botany 2010, 88(9):810-820.

59. Li S-H, Niu X-M, Zahn S, Gershenzon J, Weston J, Schneider B: Diastereomeric stilbene glucoside dimers from the bark of Norway spruce (Picea abies). Phytochemistry 2008, 69(3):772-782.

60. Jeandet P, Douillt-Breuil AC, Bessis R, Debord S, Sbaghi M, Adrian M: Phytoalexins from the vitaceae: biosynthesis, phytoalexin gene expression in transgenic plants, antifungal activity, and metabolism. Journal of Agricultural and Food Chemistry 2002, 50(10):2731-2741.

61. Brignolas F, Lacroix B, Lieutier F, Sauvard D, Drouet A, Claudot AC, Yart A, Berryman AA, Christiansen E: Induced responses in phenolic metabolism in two Norway spruce clones after wounding and inoculations with Ophiostoma polonicum, a bark beetle-associated fungus. Plant Physiology 1995, 109(3):821-827.

62. Schmidt A, Zeneli G, Hietala ACG, Fossdal CG, Krokene P, Christiansen E, Gershenzon J: Induced chemical defenses in conifers: Biochemical and molecular approaches to studying their function. In Chemical ecology and phytochemistry of forest ecosystems. Volume 39. Edited by: Romeo J. Amsterdam: Elsevier; 2005:1-28, Recent Advances in Phytochemistry.

63. Kumar S, Blaxter ML: Comparing de novo assemblers for 454 transcriptome data. BMC Genomics 2010, 11.

64. Stafford HA: Pathway to proanthocyanidins (condensed tannins), flavan3-ols, and unsubstituted flavans. Flavonoid metabolism Boca Raton, FL: CRC Press; 1990, 63-100.

65. Xie DY, Dixon RA: Proanthocyanidin biosynthesis - Still more questions than answers? Phytochemistry 2005, 66(18 SPEC ISS):2127-2144.
66. Deflorio G, Horgan G, Woodward S, Fossdal CG: Gene expression profiles, phenolics and lignin of Sitka spruce bark and sapwood before and after wounding and inoculation with Heterobasidion annosum. Physiological and Molecular Plant Pathology 2011, Corrected Proof..

doi:10.1186/1471-2229-11-154

Cite this article as: Danielsson et al: Chemical and transcriptional responses of Norway spruce genotypes with different susceptibility to Heterobasidion spp. infection. BMC Plant Biology 2011 11:154.

\section{Submit your next manuscript to BioMed Central and take full advantage of:}

- Convenient online submission

- Thorough peer review

- No space constraints or color figure charges

- Immediate publication on acceptance

- Inclusion in PubMed, CAS, Scopus and Google Scholar

- Research which is freely available for redistribution 